\title{
Primary to ternary current distribution at a vertical electrode during two-phase electrolysis
}

\author{
Ph. Mandin ${ }^{1}$, H. Roustan ${ }^{2}$, J. B. Le Graverend ${ }^{1,3} \&$ R. Wüthrich ${ }^{3}$ \\ ${ }^{1}$ LECIME UMR 7575 CNRS-ENSCP-Paris6, ENSCP, France \\ ${ }^{2}$ Alcan - Centre de Recherche de Voreppe, France \\ ${ }^{3}$ Department of Mechanical \& Industrial Engineering, \\ Concordia University, Canada
}

\begin{abstract}
During two-phase electrolysis for hydrogen or fluorine industrial production, there are bubbles that are created at vertical electrodes, which imply quite important electrical properties and electrochemical processes disturbance. Bubbles are motion sources for the electrolysis cell flow, and then hydrodynamic properties are strongly coupled with species transport and electrical performances. The presence of the bubbles modifies these global and local properties: the electrolysis cell and the primary to ternary current density distribution are modified. This disturbance leads to the modification of the local current density.

The goal of this proposition is to present the electrochemical engineering study and modelling of two-phase electrolysis properties at electrode vicinity. This work is due to the necessity for a better knowledge of the actual interface condition during electrolysis, for example to have a better process optimisation or electrode consumption prevention.
\end{abstract}

Keywords: two-phase electrolysis, modelling, electrochemical engineering.

\section{Introduction}

Gas release and induced fluid flow at electrodes are characteristic for several electrochemical processes, such as hydrogen or fluorine production. The twophase phenomena in gas evolving electrodes are in general neglected because of the major difficulty to be correctly taken into account. Nevertheless, nowadays, with the increasing interest in hydrogen production and clean, sustainable 
fluorine production for the nuclear industry, these processes have to be revisited with modern experimental and numerical tools for further optimization. Many authors [1-20] have worked on this topic and some interesting experimental observations and numerical modelling are now available for engineering optimization and process intensification.

Because of gas evolving in the gravity field, the industrial two-phase electrolysis processes generally use vertical electrodes to promote bubble detachment and avoid gas accumulation. This is the reason why the present work focuses upon vertical electrodes.

\section{Experimental set-up}

The electrochemical reactors for continuous production are opened. A pump ensures circulation through the cell and the mass flow rate is controlled. The electrodes, anode and cathode have a large surface to ensure massive production and large current intensity is applied. The average current density is from 0.1 to $1 \mathrm{~A} \mathrm{~cm}^{-2}$. The produced bubbles are accumulated at the top of the cell.

The laboratory study of these processes has lead us to define an adapted geometry for the closed electrochemical cell presented in figure 1.

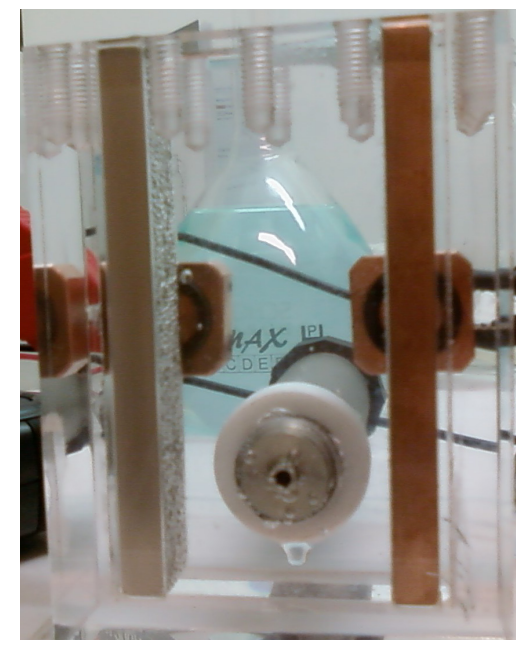

Figure 1: $\quad$ Electrochemical cell with gas evolving at electrodes.

In accordance with in situ configuration and geometry, two vertical plane electrodes separated with distance $\mathrm{d}=4.2 \mathrm{~cm}$ have been considered. The height is $\mathrm{H}=10 \mathrm{~cm}$ whereas the width is $\mathrm{l}=2 \mathrm{~cm}$. The anode is made with the usual nickel (on the left in figure 1) and the cathode is made with the usual copper (on the right in figure 1).

An Autolab PGSTAT $302 \mathrm{~N}$ is used in combination with a 20 A current booster to ensure average current density from 0 to $1 \mathrm{~A} \mathrm{~cm}^{-2}$ on the $20 \mathrm{~cm}^{2}$ electro active surface configuration studied. 
The classical alkaline water electrolysis has been chosen as a representative two-phase electrolysis process:

$$
\begin{array}{lll}
2 \mathrm{H}_{2} \mathrm{O}+2 \mathrm{e}^{-} \rightarrow \mathrm{H}_{2}+2 \mathrm{OH}_{\mathrm{aq}}^{-} & \mathbf{E}^{\circ}=-\mathbf{0 . 8 3} \mathrm{V} / \mathrm{ENH} \\
2 \mathrm{OH}_{\mathrm{aq}}^{-} \rightarrow 0.5 \mathrm{O}_{2}+\mathrm{H}_{2} \mathrm{O}+2 \mathrm{e}^{-} & \mathbf{E}^{\circ}=0.40 \mathrm{~V} / \mathrm{ENH}
\end{array}
$$

Various alkaline liquid electrolytes have been considered in the present study: $\mathrm{NaOH}$ and $\mathrm{KOH}$ with various molar concentrations.

\section{Results and discussion}

The experiments have been performed under imposed current conditions. The cell potential evolution with time was then measured for various imposed current values. After a time defined with induced hydrodynamic conditions, a steady potential is measured at the electrochemical cell. Table 1 gives the associated measured potential for different values for the imposed current, the electrolyte concentrations and nature.

As can be seen, it is easier to obey a given imposed current with $\mathrm{NaOH}$ than with $\mathrm{KOH}$ for concentration $0.1 \mathrm{M}$. However, at $1 \mathrm{M}$, the voltage to apply to impose the current is smaller with $\mathrm{KOH}$. The explanation is difficult to give and needs further modelling effort to take into account multi-physico-chemical coupled phenomena.

These measurements are really important for electrochemical engineering. The smaller the voltage is, the cheaper the hydrogen production. The hydrogen volume flow rate is directly related to the current according with the Faraday law:

$$
\mathrm{Q}_{\mathrm{H} 2}=\left(\mathrm{I}_{\mathrm{imp}} / \mathrm{n} \cdot \mathrm{F}\right)^{*}\left(\mathrm{R} \cdot \mathrm{T}_{\mathrm{amb}} / \mathrm{P}_{\mathrm{amb}}\right)
$$

with $\mathrm{Q}_{\mathrm{H} 2}$ the volume flow rate in $\mathrm{m}^{3} \mathrm{~s}^{-1}, \mathrm{n}=2$ the transferred electron number in the electrochemical reactions, $\mathrm{F}=96500 \mathrm{C} \mathrm{mol}^{-1}$ the Faraday constant, $\mathrm{R}=8.314 \mathrm{~J}$ $\mathrm{mol}^{-1} \mathrm{~K}^{-1}$ the ideal gas constant, and $\mathrm{T}_{\mathrm{amb}}=300 \mathrm{~K}$ and $\mathrm{P}_{\mathrm{amb}}=1.01310^{5} \mathrm{~Pa}$ the ambient temperature and pressure, respectively.

Table 1: $\quad$ Average voltage $U(V)$ at the electrochemical cell for various

\begin{tabular}{|c|c|c|c|c|c|}
\hline Voltage U & \multicolumn{2}{|l|}{$\mathrm{KOH}$} & \multicolumn{2}{|l|}{$\mathrm{NaOH}$} & \multirow[t]{2}{*}{$\begin{array}{l}\mathrm{Q}_{\mathrm{H} 2} \\
\mathrm{~mm}^{3} / \mathrm{s}\end{array}$} \\
\hline $\mathrm{I}_{\mathrm{imp}}(\mathrm{A})$ & $0.1 \mathrm{M}$ & $1 \mathrm{M}$ & $0.1 \mathrm{M}$ & $1 \mathrm{M}$ & \\
\hline 0.05 & $2.6 \mathrm{~V}^{*}$ & $2.0 \mathrm{~V}$ & $2.52 \mathrm{~V}$ & $2.03 \mathrm{~V}$ & 6.4 \\
\hline 0.1 & $3.4 \mathrm{~V}$ & $2.13 \mathrm{~V}$ & $3.2 \mathrm{~V}$ & $2.17 \mathrm{~V}$ & 12.8 \\
\hline 0.2 & $4.6 \mathrm{~V}$ & $2.33 \mathrm{~V}$ & $4.4 \mathrm{~V}$ & $2.45 \mathrm{~V}$ & 25.5 \\
\hline 0.5 & $8.2 \mathrm{~V}^{*}$ & $2.83 \mathrm{~V}$ & $7.9 \mathrm{~V}$ & $3.05 \mathrm{~V}$ & 63.8 \\
\hline
\end{tabular}

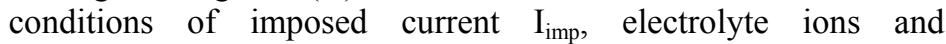
concentration. 


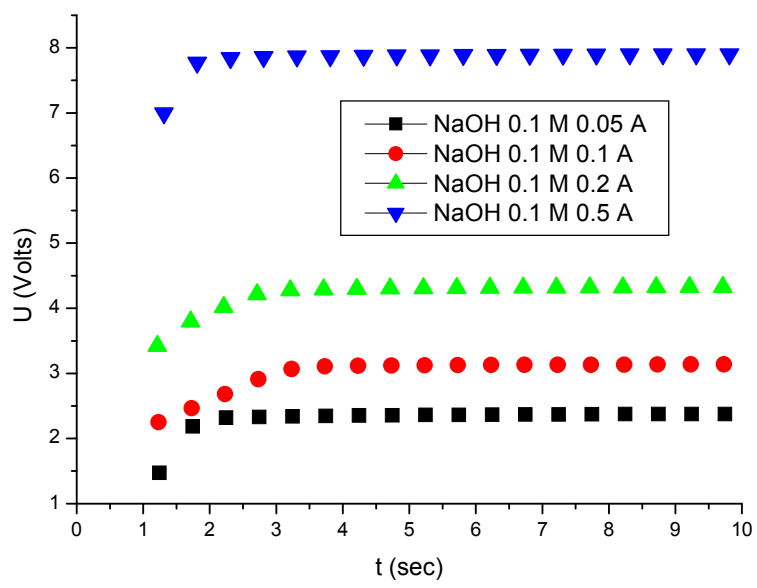

Figure 2: Evolution of the cell potential $\mathrm{U}(\mathrm{V})$ with time for $\mathrm{NaOH}$ concentration $0.1 \mathrm{M}$, for various imposed current $\mathrm{I}_{\mathrm{imp}}$ values.

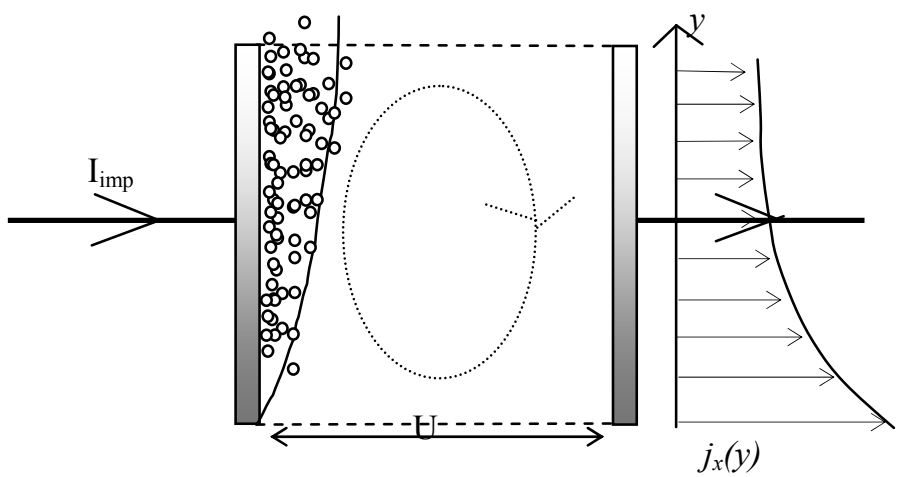

Figure 3: Vertical gas-evolving electrode: left is the geometric configuration and right is a current distribution example ( $y$ : electrode height; $j_{\mathrm{x}}(y)$ : local current density).

Figure 2 shows the evolution necessary to impose potential at the electrochemical cell to obtain a given current for various $\mathrm{NaOH}$ concentration values. As has been observed in table 1, the more concentrated the electrolyte is, the easier and cheaper the hydrogen production.

The goal of the study is now to understand and then model the reasons for such an evolution. This is the first step for optimization and process intensification. The numerical modelling is now presented. 


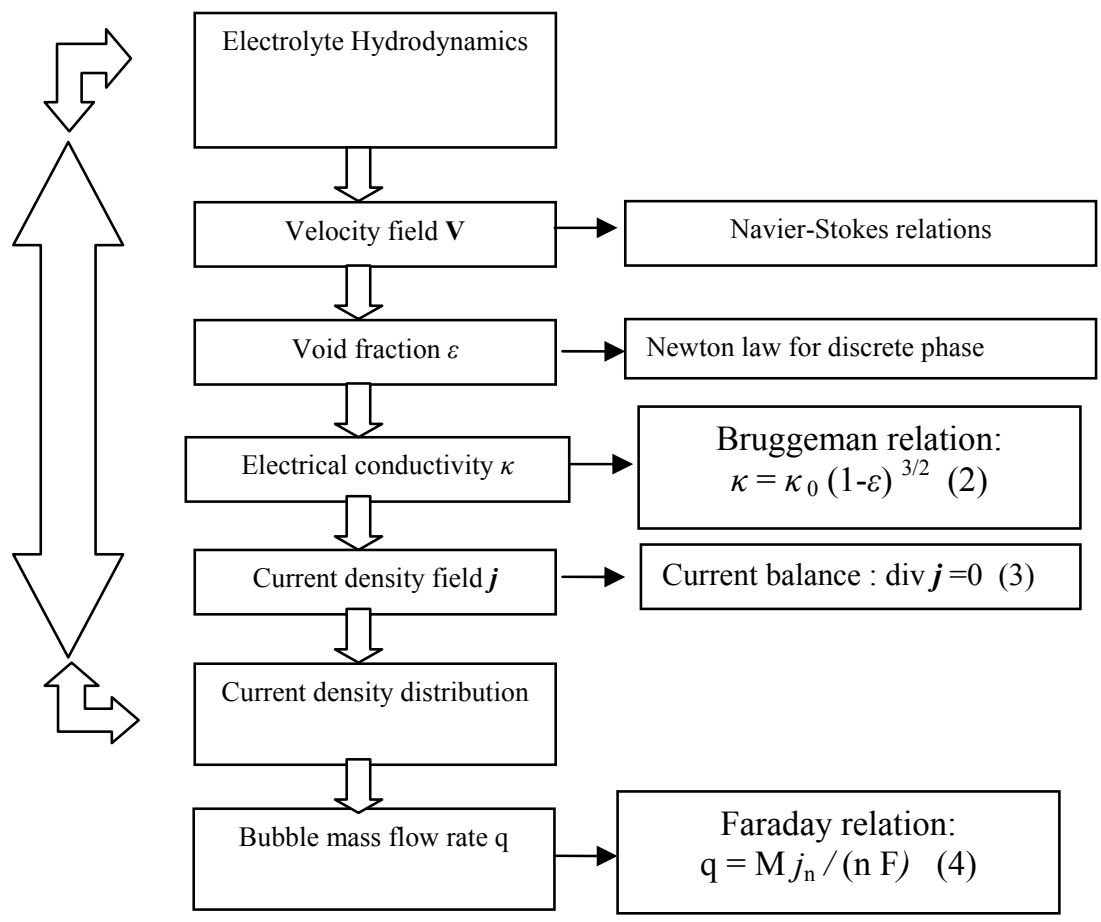

Figure 4: Calculation flow-sheet for the coupling effect in the electrochemical cell due to the presence of bubble release.

\section{Numerical modelling}

A primary current distribution at the electrodes is first developed. The schematic mathematical configuration is presented in figure 3 .

Figure 4 shows the simplified calculation algorithm for primary current distribution at the working electrode (hydrogen production). A classical CFD software is used to solve the Navier-Stokes equations under laminar hypothesis with finite volume methods. Then, for a given injected gas mass flow rate with constant spherical shape and diameter (mono disperse bubbles), each particle's trajectory is calculated according to local conditions. The bubble friction is associated to a liquid electrolyte local motion source term, which ensures strong coupling between the continuous liquid phase and the discrete bubbles phase. According to the bubble residence time, an average void fraction $\varepsilon(-)$ is calculated and then the local electrical conductivity $\kappa\left(\mathrm{S} \mathrm{m}^{-1}\right)$, the value of which is smaller than the pure liquid value $\kappa_{0}$ because of the insulating character of the gas, according to Bruggeman's law (2). Then, the local current density $\mathbf{j}\left(\mathrm{A} \mathrm{m}^{-2}\right)$ balance equation (3) can be calculated and yields to a smaller current density value where the bubble concentration is large, at the top of the electrodes. According to Faraday's law (4), the smaller the current density $\mathbf{j}$, the smaller the local gas mass flow rate $\mathrm{q}\left(\mathrm{kg} \mathrm{s}^{-1} \mathrm{~m}^{-2}\right)$. 
The Navier-Stokes calculation leads to a proposition of hydrodynamic profile, but the resulting current is not in good accord with the experimental results shown in table 1 and figure 2 . The main reason is the great difficulty in correctly modelling the hydrodynamic properties. Then, to validate the hydrodynamic model itself, it has been decided to perform some experimental local field velocity experiments using a PIV laser plane. The bubbles are supposed to perfectly follow the local flow direction and magnitude because they are small enough. A fast CCD camera is used, which registers 170 picture couples at a frequency of $15 \mathrm{~Hz}(66.67 \mathrm{~ms})$. Each couple of picture is measured with a delay of $8 \mathrm{~ms}$. Then, the post-processing of the picture couple allows the definition of a local velocity vector according to the bubble's displacements during the $8 \mathrm{~ms}$ between the two post-treated pictures. The experimental set-up is presented in figure 5 .

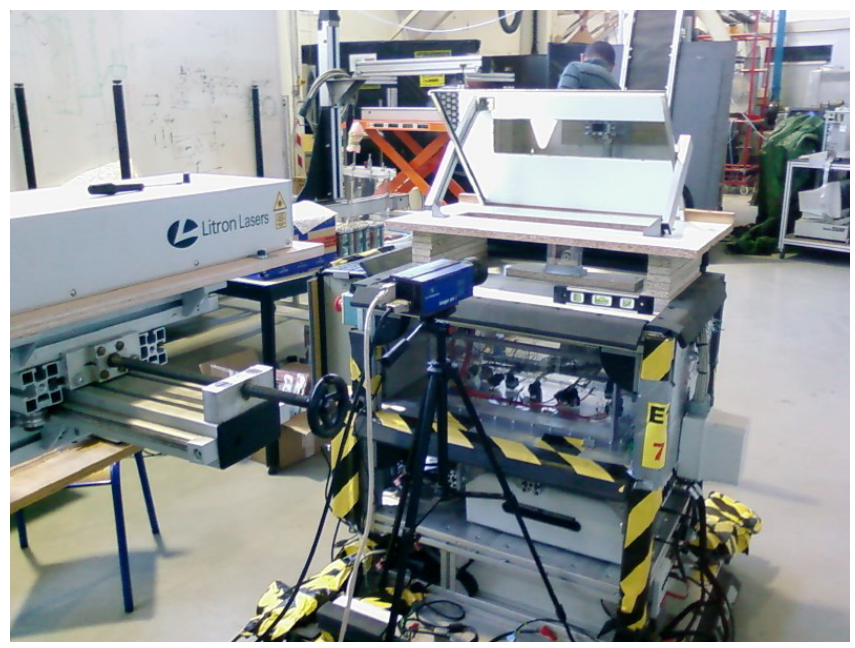

Figure 5: PIV measurements experimental set-up.
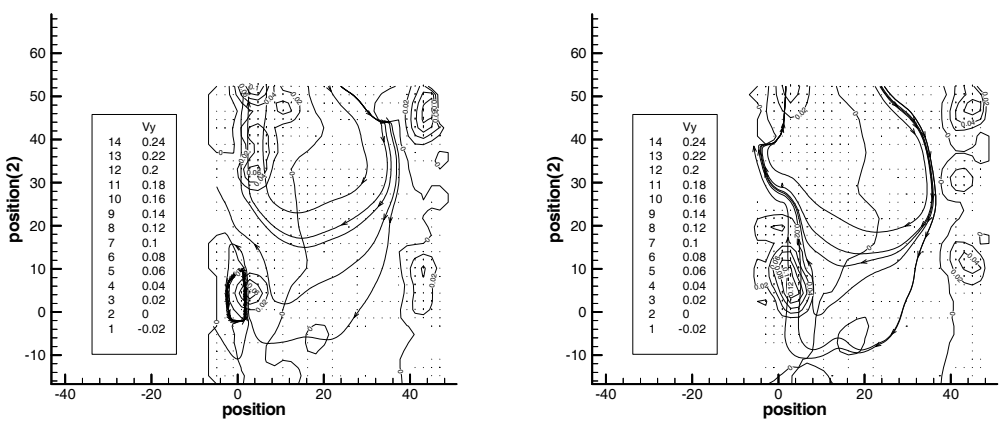

Figure 6: Unsteady vertical velocity component contours and stream function at I=1A, after $220 \mathrm{~s}$ electrolysis (left) and $220 \mathrm{~s}+80 \mathrm{~ms}$ (right). 
For each electrolysis condition, four times 170 couple of pictures ( $8 \mathrm{~ms}$ time difference) have been measured at $15 \mathrm{~Hz}(66.7 \mathrm{~ms})$ during the unsteady and steady regime. The post-processing of the results is in progress, but leads to interesting and difficult to understand results and consequences.

The electrodes with bubbles evolving seem to lead in the confined electrochemical cell to a hydrodynamic "puffing phenomenon", clearly three dimensional and unsteady in the cell. Then all the coupled phenomena, transports and reactions are affected and should actually be three dimensional and unsteady.

The primary current distribution modelling described is to be completed with an accurate homogeneous and surface realistic chemistry modelling. This is called the ternary current distribution modelling. This modelling needs the knowledge of transport kinetic properties (diffusion coefficients), speciation and reactions, which occur in the cell, with the associated thermodynamic and/or kinetic reactive properties. An example of local speciation and chemistry is given in figure 7.

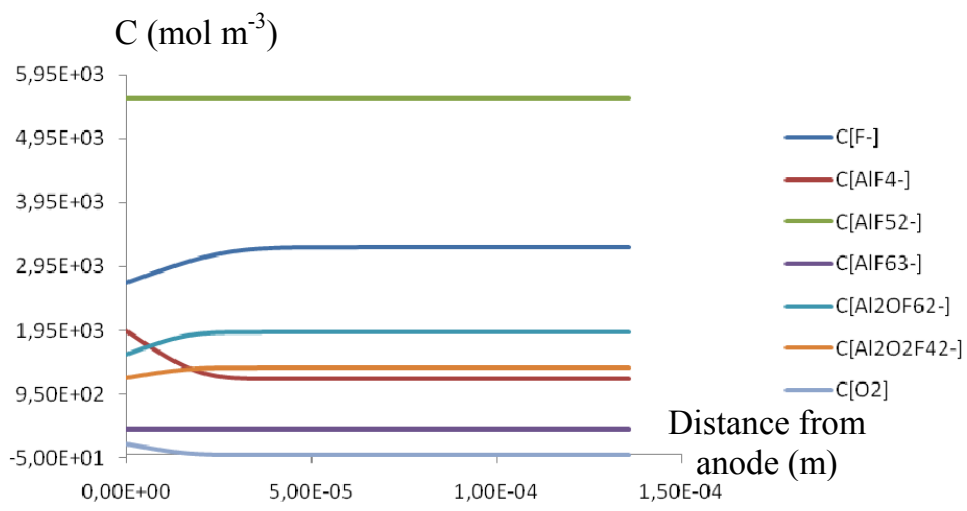

Figure 7: $\quad$ Speciation profiles in the anode vicinity in the case of aluminium production according to the Hall-Heroult process [12].

\section{Conclusion and interest in zero gravity experiments}

As shown previously, the hydrodynamic properties are really difficult to model: both electrodes are naturally induced motion sources with one or two phase flows; this flow can be from laminar to turbulent and really confined. This is the reason why many years researchers $[7,8]$ have tried to avoid this difficulty with zero gravity experiments. The Japanese team has performed its experiments in a drop tower, whereas we plane to perform zero gravity in an Airbus A300-0G aircraft. This is possible if the plane follows what is called a parabolic trajectory (see figure 8 left). Various electrolysis experiments are performed for different liquid electrolyte and electrode conditions and each time the electrical and video properties are measured. At the beginning of a parabole the gravity level is $1 \mathrm{G}$ (normal); first the plane is accelerated at $2 \mathrm{G}$ and after 20 seconds, the engines are turned off and the zero gravity experiment begins at 22 seconds. After this the 
engines are turned on and the plane accelerates at $2 \mathrm{G}$ for 20 seconds to stabilize and access the normal horizontal trajectory. At $1 \mathrm{G}$ and $2 \mathrm{G}$ the bubbles are produced and evolve vertically; at zero gravity their motion is "frozen" and they stop almost immediately. They have no motion at 22 seconds (fig. 8 right). The experimental measurement treatments are in progress. These experiments then allow the study of the gas, bath and electrode material in perfect absence of any convective transport during this time, which is really interesting for the twophase electrolysis modelling effort in progress.
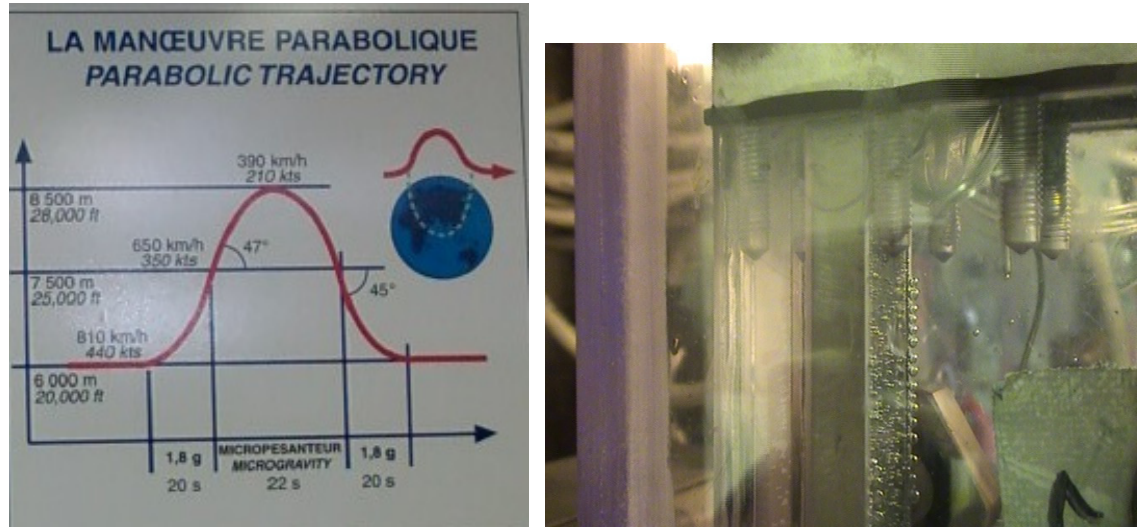

Figure 8: Description of the parabolic trajectory (left) and presentation of the bubbles behaviour for $1 \mathrm{G}, 2 \mathrm{G}$ and $0 \mathrm{G}$ (right).

\section{Acknowledgements}

The authors are grateful to Alcan, CEA and AREVA and the French project AMELHYFLAM (ANR 2007) for their financial support. (AMELHYFLAM is the French acronym for the programme to improve Hydrogen, Fluorine and Alumina industrial production processes by coupled modelling of two-phase and electrochemical phenomena).

\section{References}

[1] F. Jomard, J.P. Feraud, J.P. Caire, International Journal of Hydrogen Energy 33 (2008) 1142-1152

[2] H. Kellogg, Anode Effect in Aqueous Electrolysis, Journal of the Electrochemical Society, vol $97 \mathrm{~N}^{\circ} 4$ (1950)

[3] Kazuhisa Azumi, Tadahiko Mizuno, Tadashi Akimoto, and Tadayoshi Ohmori, Light Emission from Pt during High-Voltage Cathodic Polarization J. Electrochem. Soc. 146 (1999) 3374

[4] L.J.J. Janssen, J.G Hoogland, The effect of electrolytically evolved gas bubbles on the thickness of the diffusion layer, Electrochimica Acta, Vol. 15 ( 1970) 1020 
[5] L.J.J Janssen, C.W.M.P Sillen, E. Barendrecht et S.J.D Van Stralen, Bubble behaviour during oxygen and hydrogen evolution at transparent electrodes in $\mathrm{KOH}$ solution, Electrochimica Acta, Vol. 29, No 5 (1984) pp633-642

[6] S.M. Korobeinikov, A.V. Melekhov, Yu. N. Sinikh and Yu. G. Soloveichik, Effect of strong electric field on the behaviour of bubbles in water, in High Temperature, Vol. 39, No 3 (2001) pp368-372

[7] H. Matsushima, T. Nishida, Y. Konishi, Y. Fukunaka, Y. Ito, K. Kuribayashi, Water electrolysis under microgravity: Part I. Experimental technique, Electrochimica Acta, Volume 48, Issue 28 (2003) pp41194125

[8] H. Matsushima, Y. Fukunaka, K. Kuribayashi, Water electrolysis under microgravity: Part II. Description of gas bubble evolution phenomena, Electrochimica Acta, Volume 51, Issue 20 (2006) pp4190-4198

[9] H. Vogt, Ö. Aras, R. J. Balzer, The limits of the analogy between boiling and gas evolution at electrodes, International Journal of Heat and Mass Transfer, Volume 47, Issue 4 (2004) pp787-795

[10] H. Vogt, R.J. Balzer, The bubble coverage of gas-evolving electrodes in stagnant electrolytes, Electrochimica Acta, Volume 50, Issue 10 (2005) pp2073-2079

[11] J. Eigeldinger, H. Vogt, The bubble coverage of gas-evolving electrodes in a flowing electrolyte, Electrochimica Acta, Volume 45, Issue 27 (2000) pp4449-4456

[12] Ph. Mandin, J. Hamburger, S. Bessou, G. Picard, Calculation of the current density distribution at vertical gas-evolving electrodes, Electrochimica Acta, Volume 51, Issue 6 (2005) pp1140-1156

[13] R Wüthrich, L.A. Hof, A. Lal, K. Fujisaki, H. Bleuler, Ph. Mandin, G. Picard, Physical principles and Miniaturization of Spark Assisted Chemical Engraving (SACE), J of Micromech. Microeng., 15 (2005) 268275

[14] Ph. Mandin, H. Roustan, R. Wüthrich, J. Hamburger \& G. Picard, Twophase electrolysis process modelling: from the bubble to the electrochemical cell scale Transactions on Engineering Sciences, 2007 WIT Press, Simulation of Electrochemical Processes II, p73

[15] Ph. Mandin, A. Ait Aissa, H. Roustan, J. Hamburger, G. Picard, Twophase electrolysis process: from the bubble to the electrochemical cell properties, Chemical Engineering and Processing: Process intensification, 47 (2008) pp1926-1932

[16] C. Gabrielli, F. Huet, R.P. Nogueira, Fluctuations of concentration overpotential generated at gas-evolving electrodes, Electrochimica Acta, Volume 50, Issue 18 ( 2005) pp3726-3736

[17] Allen J. Bard and Larry R. Faulkner, Electrochemical Methods-

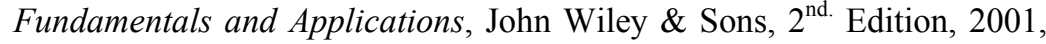
243. 
[18] F. Lapicque, Electrochemical Engineering: An Overview of its Contributions and Promising Features, Chemical Engineering Research and Design, Volume 82, Issue 12 (2004) pp1571-1574

[19] I. Zaytsev, G. Aseyev: Properties of Aqueous Solution of Electrolytes, CRC Press, Boca Raton, Ann Arbor, London, Tokyo (1992)

[20] R. Wüthrich, Ch. Comninellis, H. Bleuler: Bubble evolution on a vertical electrode under extreme current densities, Electrochimica Acta 50 (2005) pp5242-5246 